\title{
PRODUCCION DE CELULASAS POR CEPAS DE ASPERGILLUS NIGER Y TRICHODERMA HARZIANUM AISLADAS DE SUELOS TRATADOS CON FLUROXYPYR. ESTUDIO PRELIMINAR. I.
}

\author{
Alvarez, D.P.; Rossi, Gabriela S. \\ Centro de Referencia en Micología (CEREMIC). Facultad de Ciencias \\ Bioquímicas y. Farmaceúticas. Universidad Nacional de Rosario. \\ Suipacha 531. Rosario (2000). Santa Fe. República Argentina.
}

Palabras Clave: Aspergillus niger, Trichoderma harzianum, cepas celuloliticas, suelos, herbicidas.

Key Words: Aspergillus niger, Trichoderma harzianum, cellulolytic strains, soils, herbicides.

\section{RESUMEN}

Debido a que en suelos con siembras de trigo tratados con un herbicida post emergente (Fluroxypyr), seobservó enmedios selectivos parahongos celulolíticos, una disminución de la frecuencia de cepas de A. niger y T.harzianum, en relación a la alcanzada en muestras testigo. Esta situación nos motivó a evaluar si el efecto fungistatico de este herbicida podria alterar la capacidad celulolitica de estos hongos.

Estudiando su desarrollo in vitro frente a la celulosa nativa y carboximetilcelulosa, mediante la producción de exo y endoglucanasas extracelulares, observamos que ambas cepas de Aspergillus no mostraron diferencias en su actividad celulolitica, pero si la de Trichoderma aislada de suelo con Fluroxypyr, la cual hidroliza en menor grado celulosa nativa $y$ carboximetilcelulosa.

De acuerdo con ello, la disminución de la frecuencia de Aspergillus niger en las muestras de suelos, podria obedecer a factores de competencia entre las poblaciones celuloliticas y en las de Trichoderma a una disfunción enzimática a nivel de las celulasas o un efecto mutagénico producido por el herbicida en esta cepa.

\section{INTRODUCCION}

Diversos grupos fúngicos utilizan a la celulosa como fuente de carbono y de energía, la incorporación a los suelos de tal carbohidrato a través de restos vegetales o del llamado abono verde, provoca un incremento de la micota celulolítica, particularmente si se suplementa

\section{SUMMARY}

/Celluslases production in Aspergillus niger and Tricoderma harzianum isolated from soils treated with Fluroxypyr. Prelineinary Study I.]

Aspergillus niger and Trichoderma karzianum cellulolytic strains were isolated in selective medium for fungi from cultivable soils treated with Fluroxypyr a post emergent herbicde, with less frequency than in the same soils not treated with this pesticide.

The cellulolytic activity of the said strains was studied in order to verify whether the decrease in isolation was due to a disminution of that capacity. With this aim its capacity to degrade native cellulose and carboximetilcellulose was tested, through the production of extracellular exo and endo glucanases, in a medium in which cellulose is the only source of carbon. The cellulolytic activity was evaluated in aliquots of the filtrate of the development, in front of filter paper grinding and carboximetylcellulose.

As a result, neither of the Aspergillus strains showed differences in its cellulolytic actvity. But the Trichoderma strains did: the strain isolated from Fluroxypyr treated soil, hydrolyzed native cellulose, as paper filter grinding and carboxymetilcellulose, to a lesser extent. Thus the decrease in frequency of Aspergillus niger in soil samples could have been due to competition factors between cellulolytic populations, whereas that of Trichoderma harzianum strains to an enzymatic disfunction at the level of cellulases or to a mutagenic effect produced by the herbicide.

tal abono con el agregado de nitrógeno. La bioconversión de los materiales celulósicos o lignocelulósicos puede llevar a generar azúcares, alcoholes, adhesivos y solventes (5). 
Se realiza principalmente por la acción enzimática de exo y endo (1-4) glucanasas y celobiasas extracelulares que actúan sinergicamente; las endoglucanasas desdoblan las uniones glucosídicas de la fracción amorfa de la celulasa, liberando cadenas más cortas de oligosacáridos, de manera que la región cristalina del polímero queda expuesta a la acción de exoglucanasas con la producción de unidades de celobiosa que las glucosidasas las hidrolizan a glucosa (1) (6).

La síntesis del sistema celulasas es regulada por inducción y por represión catabólica y no.en todos los hongos celulolíticos, alcanza tal nivel como para generar azúcares fermentables in vitro. Esta actividad enzimática, esta condicionada por multiples factores variables con la temperatura, $\mathrm{pH}$, humedad, presencia de otros carbohidratos y proporción de lignina relacionada al tipo de estructura que integran en el material vegetal (11).

En el aislamiento que realizamos de la micota celulolítica de suelos cultivados y con aplicación de un herbicida( Fluroxypyr), se observó una disminución de la frecuencia de cepas de Aspergillus niger y Trichoderma harzianum, en relación a la alcanzada en muestras testigo, surgió entonces, el interés por conocer, si esa acción limitante, reflejaba una disminùción de la capacidad celulolítica de tales cepas.

\section{MATERIALES Y METODOS}

Se trabajó con dos cepas de Aspergillus niger

(I y II) y dos de Trichoderma harzianum, aisladas de suelos con Fluroxypyr (I) y sin agregado del fitotóxico (II).

Para el estudio de la actividad celulolítica, las colonias deTrichoderma harzianum mantenidas en medio de Agar extracto de malta y las de Aspergillus niger en Agar Czapek, se activaron en los mismos medios durante un periodo de 7 días a $28^{\circ} \mathrm{C}$, con la finalidad de obtener una suspensión de conidios en agua destilada estéril, hasta un promedio de $1 \times 10^{4}$ a $1 \times 10^{5}$ conidios por $\mathrm{ml}$.

El desarrollo de las cepas y la inducción del complejo celulasas, se hizo por siembra de $1 \mathrm{ml}$ de ese inóculo por duplicado en $75 \mathrm{ml}$ del medio base de Theodorov et al. (10), con un $\mathrm{pH}$ final de 5.5, reemplazando la carboximetilcelulosa por la molienda de papel de filtro (Whatman CC31): $500 \mathrm{mg}$, en el volumen del medio indicado, que se distribuyó en Erlenmeyer de $125 \mathrm{ml}$. Se incubaron a $28^{\circ} \mathrm{C}$, en agitador mecánico a 120 r.p.m., durante 12 días.

Cada 48 horas, se procedió al filtrado de los desarrollos mediante filtro de fibra de vidrio (Whatman
$\mathrm{CF} / \mathrm{F}$ ). Se determinó el peso seco, las proteínas solubles por filtrado y la actividad sobre papel filtro (APF) de las endoglucanasas como carboximetilcelulasa.

La determinación del peso seco representa el peso micelial más el residual de la molienda de papel de filtro, previamente secados en estufa a $37^{\circ} \mathrm{C}$ hasta peso constante y se calculó en mg por tiempo del desarrollo. Las proteínas solubles fueron dosadas de acuerdo al método de Henry, R.J. (3) en milígramos por $\mathrm{ml}$ del filtrado.

En los ensayos enzimáticos se valoraron:

a) La actividad de las celulasas sobre papel filtro: $2 \mathrm{ml}$ de cada filtrado llevado a $\mathrm{pH} 4.8$, con $2 \mathrm{ml} \mathrm{de}$ buffer de citrato con un $\mathrm{pH} 4.8$ y $20 \mathrm{mg}$ de molienda de papel filtro (Whatman CC31), se incubaron a $50^{\circ} \mathrm{C}$, durante 60 minutos. Previa centrifugación, en el sobrenadante se adosaron los azúcares reductores por el método de Somogyi y Nelson (8) (7).

b) Las endoglucanasas (carboximetilcelulasas): $2 \mathrm{ml}$ de cada filtrado, más $1 \mathrm{ml}$ de citrato a pH 4.8, se incubaron con $1 \mathrm{ml}$ de carboximetilceluiosa (Grado B-50 I.C.I. Ltd. Cheshire IK) al 2\%, a $50^{\circ} \mathrm{C}$, durante 60 minutos. Los azúcares reductores fueron valorados como en el ensayo anterior y se expresaron como micromoles de glucosa por ml del filtrado.

\section{RESULTADOS Y DISCUSION}

En la Figura 1 a, la curva de crecimiento de las cepas estudiadas de acuerdo a los datos promedios del pesoseco, en relacióna lostiempos del ensayo enzimático, muestra una fase log. dentro de las 24 horas; para todos los desarrollos. El menor crecimiento corresponde a la cepa de $T$. harzianum I, es decir aislada de suelo con desmalezante.

El tiempo de agotamiento del sustrato en las cepas de Aspergillus, está entre 96 y 144 horas y para las de Trichoderma es de 144 a 192 horas.

Estos datos del crecimiento se correlacionan con los obtenidos en el dosaje de las proteínas solubles, Fig. 1b, que según trabajos de Sternberg (9), son indicativos de la producción de celulasas, que en este caso se puede aplicar a la síntesis de endoglucanasas que metabolizan la carboximetilcelulosa empleada para valorar la actividad enzimática y no en la misma medida, para otros componentes del complejo celulasas, que degradan la celulosa nativa o cristalina del papel filtro: tal como lo muestran las Figuras $2 \mathrm{a} \mathrm{y} \mathrm{b.}$

La menor actividad sobre este sustrato puede obedecer a la fuerte adsorción enzimática del mismo oa un diferente grado de formación de las correspondientes 
Fig 1.

a) Peso seco de la masa micelial más el residual del papel filtro $\longrightarrow$ Trichoderma harzianum I. 1 T.harzianum II. b) Proteimas solubles en el filtrado del cultivo. Aspergillus niger I. $0-0$ A.niger II
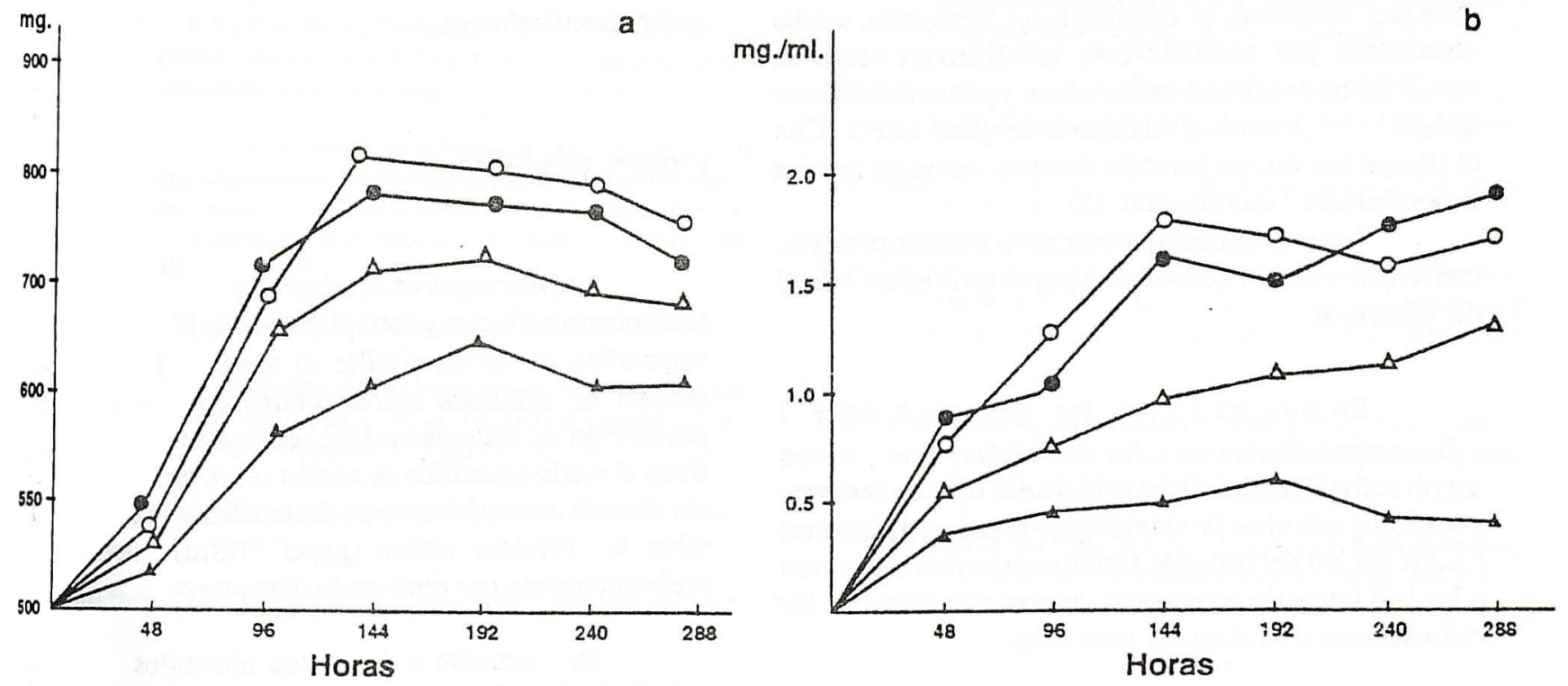

Fig 2.

a) Actividad de las celulasas sobre papel filtro. b) sobre carboximetilcelulosa. A.niger I $\multimap$ A.niger II $\longrightarrow$ T. harzianum I $\stackrel{\triangle}{\triangle}$ T. harzianum II
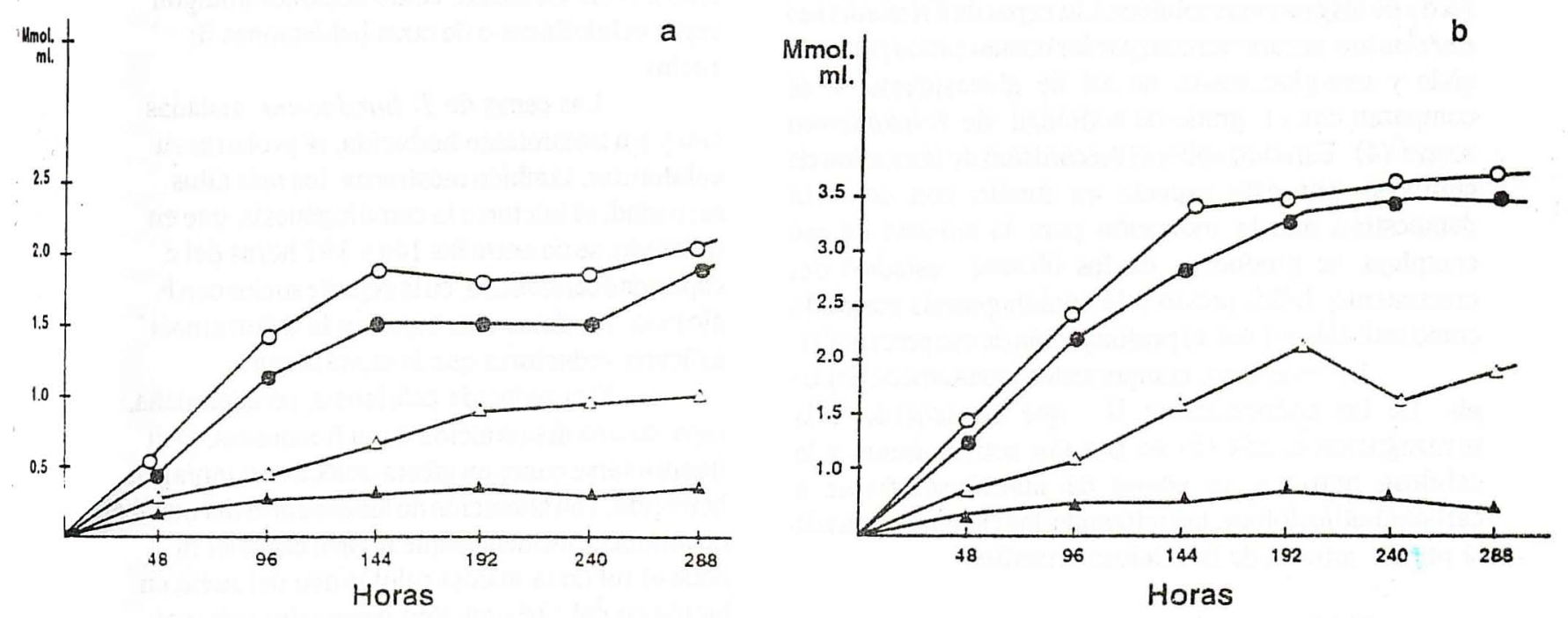
enzimas. Así se ha comprobado utilizando a la celobiosa como sustrato del desarrollo de Sporotrichum thermophile y haciendo el fraccionamiento y análisis de los distintos componentes de las celulasas producidas, donde la mayor actividad, al comienzo del desarrollo, estaba represetada por endocelulasas, identificadas como de tipo II frente a carboximetilcelulosa, y por endocelulasas de tipo I y III, cuando el sustrato es celulosa nativa. Con el tiempo esa última fracción decrece, mientras que las endocelulasas I incrementan (2).

Las exocelulasas parecen estar siempre presente, con mayor o menor actividad, excepto en la etapa inicial del desarrollo.

En la figura 2 a y $\mathrm{b}$, las cepas de $A$. niger I y II, comparativamente a las de Trichoderma, tienen mayor actividad celulolítica para los dos tipos de sustratos y los datos más altos de micromoles de azúcar reductores ( 3.261 por $\mathrm{ml}$ del filtrado), frente a carboximetilcelulosa a las 144 horas de incubación, lo que coincide con ias estimaciones más altas del peso seco.

La producción de celulasas por $T$. harzianum I es marcadamente menor con respecto a las otras tres cepas. sobre todo frente a la celulosa nativa y se correlaciona también con las determinaciones del peso seco y de las proteínas solubles. Las cepas de Trichoderma harzianum secaracterizan por ser buenas productoras de endo y exo-glucanasas, no así de glucosidasas, si se comparan con el grado de actividad de Trichoderma reesei (4). Estudios sobre el mecanismo de liberación de celulasas por esta especie en medio con celulosa demuestran que la inducción para la sintesis de ese complejo. se producen en los últimos estadios del crecimiento hifal, previo a la conidiogénesis actuando como estímulo o sobre la prolongación de ese proceso (4).

En este caso, componentes enzimáticos del tipo de las endocelulasas II, que de acuerdo a la investigación citada (2) no son tan activas frente a la celulosa nativa y se ponen de manifiesto frente a carboximetilcelulosa, hidrolizando las cadenas cortas de la región amorfa de la celulosa cristalina.

Si bien todos los componentes celulolíticos se forman durante la primera fase del desarrollo, pueden variar en el tiempo, según el sustrato y la proliferación del cultivo, mostrando diferencias en sus respectivos grados de formación, con un espectro variado para cada etapa del crecimiento. Este es el problema central en la biología de la celulolisis, donde diferentes cepas pueden mostrar un sistema regulatorio similar o distinto.
Para T. harzianum I, a las 192 horas del crecimiento en celulosa nativa se tuvieron los dosajes mayores de azúcares reductores: 0,632 micromoles de glucosa por acción de las celulasas del filtrado, sobre carboximetilcelulosa.

\section{CONCLUSIONES}

Las dos cepas de $A$. niger, aisladas de suelos sin tratamiento herbicida y con aplicación deFluroxypyr han respondido en forma similar al sustrato inductor del sistema de celulasas extracelulares con una elevada producción de endoglucanasas (carboximetilcelulasas). Dado el modo específico de acción sobre ese compuesto. esa síntesis enzimática no se desmostró en igual grado sobre la celulosa nativa (papel filtro) degradada preferentemente por otras endoglucanasas.

De acuerdo a los datos obtenidos sobre la actividad celulolítica de la cepa de Aspergillus niger I. la disminución de su frecuencia en suelos con tratamiento herbicida. no parecen responder a una alteración del sistema celulasas, por el agroquímico o sus residuales. sino a otras variables, como acciones antagónicas entre cepas celuloliticas o de otras poblaciones fúngicas de los suelos.

Las cepas de T. Barzianum aisladas de suelo con y sin tratamiento herbicida, al probarse su actividad celulolítica, también mostraron los más altos niveles, de actividad, al iniciarse la conidiogénesis, que en el medio utilizado, se da entre las 144 y 192 horas del cultivo. Tal capacidad celulolitica, en la cepa de suelos con Fluroxypir. alcanzó los datos más bajos en la determinación de los azúcares reductores que la cuantifican.

Esta reducida celulolisis, se acompaña, en esa cepa, de una disminución de su frecuencia, lo que podría interpretarse como un efecto selectivo o mutagénico del herbicida, conalteración de los efectoresdel metabolismo celulolítico; influencia que reviste especial importancia. dado el rol de la micota celulolítica del suelo en el ciclo biológico del carbono. Son necesarios mayores estudios al respecto. 


\section{REFERENCIAS}

1.-Beltrance, P. L.; Carniti, P.; Focker, B.; Marzeti, A. \& Sarto, V. (1984). Enzymatic hydrolysis of cellulosic materials; a kinetic study. Biotechnol. Bioeng. $26: 1233-1238$.

2.-Canevascini, G.; Fracheboud, D. \& Meier, H. (1983).Fractionation and identification of cellulases and other extracellular enzy. mes, produced by Sporotrichum (Chrysosporium) thermophile during growthon cellulose or cellobiose. Can. J.Microbiol. 29 : 1079-1080.

3.-Henry,R.J. (1969). Química Clínica. Tomo I. Edit. Jims. pp. 224-226.

4.Jackson, M.A. \& Talburt, D.E.(1988). Mechanism for Bglucosidase release into cellulose-grown Trichoderma reesei, culture supernatans. Experimental Mycology 12 : 203-216.

5.-Mandels, M.(1985). Applications of cellulases. Biochem. Soc. Trans. $13: 414-415$.

6.-Mc Hale, A. (1981). The cellulolytic system of Talaromyces emersonii.
Identification of the components produced during growth on cellulosic media. Biochem. Biophys. Acta 662 : 145-151.

7.-Nelson, N. (1944). A photometric adaptation of the Somogyi method for the determination of glucose. J. Biol. Chem. $153: 375-380$.

8.-Somogyi, M. (1952). Notes on sugar determination. J. Biol. Chem. 195: 19-23.

9.-Sternberg, D. \& Mandels (1980). Regulation of the cellulolytic system in Trichoderma reesei by sophorose: induction of cellulase and repression of D-glucosidase. J. Bacteriol. 59: 607-613.

10.-Theodorov, M.K.; Basin, M. J. \& Trinci, A.P.J. (1980). Cellulose degradation in a structure ecosystem which in analogous to soil. Trans. Br. Mycol. Soc. $75: 445-450$.

11.-Wood, T.M. \& Mc Grae, S.J. (1979). Synergism between enzymes involved in the solubilization of native cellulose. Adv. Chem. Serv., 181-209. 